University of Wollongong

Research Online

Faculty of Social Sciences - Papers (Archive) Faculty of Arts, Social Sciences \& Humanities

$1-1-2017$

Enjoyment and behavioral intention predict organized youth sport participation and dropout

Lauren Gardner

University of Wollongong, lag994@uowmail.edu.au

Christopher A. Magee

University of Wollongong, cmagee@uow.edu.au

Stewart A. Vella

University of Wollongong, stvella@uow.edu.au

Follow this and additional works at: https://ro.uow.edu.au/sspapers

Part of the Education Commons, and the Social and Behavioral Sciences Commons

Research Online is the open access institutional repository for the University of Wollongong. For further information contact the UOW Library: research-pubs@uow.edu.au 


\title{
Enjoyment and behavioral intention predict organized youth sport participation and dropout
}

\author{
Abstract \\ Background: Dropout from organized youth sport has significant adverse health implications. Enjoyment \\ and behavioral intentions have consistently been linked with participation and dropout; however, few \\ studies have investigated these links using a prospective design. This study explored whether enjoyment \\ and intentions to continue predicted dropout behavior at 1-year follow-up. Methods: Questionnaires were \\ completed by 327 regular sport participants (mean age $=13.01 \mathrm{y}$ at baseline). After 1 year, 247 individuals \\ (75.5\%) continued participating in their main sport and 26 individuals (8\%) dropped out. A hierarchical \\ logistic regression model estimated the probability of dropout. In step 1 , the following covariates were \\ included: age, sex, competition level, perceived competence, parental support, coach-athlete relationship, \\ friendship quality, and peer acceptance. In step 2, enjoyment and intentions to continue were included. \\ Results: Step 1 indicated that age, parental support, coach-athlete relationship quality, and peer \\ acceptance were significantly associated with dropout. Step 2 explained further variance in dropout, with \\ both enjoyment and intentions inversely associated with dropout. Peer acceptance was the only covariate \\ to remain significantly associated with dropout in step 2. Conclusions: Findings support the use of \\ enjoyment and behavioral intentions as indicators of sport participation/dropout behavior and may aid \\ the development of interventions aimed at preventing future dropout.

\section{Disciplines \\ Education | Social and Behavioral Sciences}

\section{Publication Details} \\ Gardner, L., Magee, C. \& Vella, S. (2017). Enjoyment and behavioral intention predict organized youth sport \\ participation and dropout. Journal of Physical Activity and Health, 14 (11), 861-865.
}


Enjoyment and Intentions as Predictors of Dropout

1

2

3

4

5

6

7

8 Manuscript type: Brief report

9 Key words: Sport attrition, sport withdrawal, adolescence

10 Abstract word count: 200

11 Manuscript word count: 2745

12 Date of manuscript resubmission: $6^{\text {th }}$ March 2017 
Enjoyment and Intentions as Predictors of Dropout

Abstract

\section{Background}

Dropout from organized youth sport has significant adverse health implications. Enjoyment and behavioral intentions have consistently been linked with participation and dropout; however few studies have investigated these links using a prospective design. This study explored whether enjoyment and intentions to continue predicted dropout behavior at oneyear follow-up.

\section{Methods}

Questionnaires were completed by 327 regular sports participants $\left(M_{\mathrm{age}}=13.01\right.$ years at baseline). After one-year, 247 individuals (75.5\%) continued participating in their main sport and 26 individuals (8\%) dropped out. A hierarchical logistic regression model estimated the probability of dropout. In step 1, the following covariates were included: age, sex, competition level, perceived competence, parental support, coach-athlete relationship, friendship quality, and peer acceptance. In step 2, enjoyment and intentions to continue were

27 included.

\section{Results}

Step 1 indicated that age, parental support, coach-athlete relationship quality, and peer acceptance were significantly associated with dropout. Step 2 explained further variance in dropout, with both enjoyment and intentions inversely associated with dropout. Peer acceptance was the only covariate to remain significantly associated with dropout in step 2 .

\section{Conclusions}

34 Findings support the use of enjoyment and behavioral intentions as indicators of sport participation/dropout behavior and may aid the development of interventions aimed at preventing future dropout. 
Enjoyment and Intentions as Predictors of Dropout

Enjoyment and Behavioral Intention Predict Organized Youth Sport Participation and

$$
\text { Dropout }
$$

Organized sport is globally one of the most popular types of physical activity among youth, ${ }^{1}$ and has many immediate and long-term benefits across multiple domains (e.g., physical, psychosocial, financial). ${ }^{2}$ However, dropout from youth sport remains a major issue during adolescence, ${ }^{3}$ and predicts adverse outcomes (relative to continued participation in sport) including decreased mental health and well-being. ${ }^{4,5}$ Despite this, research exploring dropout is scarce and more studies are needed to better understand and prevent dropout. Methodological challenges to researching sport dropout include the need for longitudinal designs with large samples that can be followed prospectively to identify individuals who drop out. This is particularly difficult when recruiting through sports clubs, as individuals who continue participating but change to another club (e.g., at a higher competition level) may be incorrectly classed as having dropped out of the sport completely. Thus, few prospective studies have been conducted, and most studies have been retrospective or have used proxy measures of dropout based on commonly identified reasons for withdrawal. $^{3,6}$ Two frequently used proxy measures are enjoyment and behavioral intentions (e.g., $\left.{ }^{7,8}\right)$, but the validity of these as predictors of participation and dropout behavior over time are not known. In this paper, we investigate whether enjoyment and behavioral intentions translate into sport participation behavior and can therefore be used as valid indicators within youth sport research.

Enjoyment in youth sport is considered the greatest predictor of commitment and lack of enjoyment is the most frequently cited predictor of dropout. ${ }^{6,9}$ Theories such as the Fun Integration Theory (FIT), ${ }^{9}$ provide a framework for understanding the determinants of enjoyment (or fun). For example, FIT proposes 81 determinants important to youth sport participation, which reflect 11 distinct dimensions and four fundamental underlying tenets: 
social fundamentals (includes team friendships, team rituals, and positive team dynamics), internal fundamentals (includes learning and improving, trying hard, and mental bonuses), external fundamentals (includes positive coaching, game time support, and swag), and contextual fundamentals (includes practices and games). Many studies support the link between enjoyment and sport participation; however the relationship has typically been investigated retrospectively, where participants recalled their reasons for dropout after it had occurred. ${ }^{6}$ Although time- and cost-efficient, these retrospective approaches are likely to be inaccurate, biased (e.g., recall bias), and provide only partial insight into the temporal associations between variables. ${ }^{10}$ Prospective studies examining the temporal associations between enjoyment and dropout are limited. One available study ${ }^{11}$ reported a non-significant association, but this study could not distinguish between individuals who dropped out of the sport completely or continued participating at another club. The study therefore assessed team-specific dropout, rather than sport-specific or complete dropout. Prospective research that follows individuals who may discontinue playing for one club/sport but continue participating for another club/different sport is needed to clarify whether enjoyment is a valid predictor of sport participation in these instances. In contrast to the FIT, the Theory of Planned Behavior (TPB) ${ }^{12}$ focuses on cognitive antecedents of behavior. TPB centers on an individual's behavioral intentions which are determined by their attitude toward the behavior, subjective norms, and perceived behavioral control. ${ }^{12}$ Consistent with the TPB, intentions have been shown to be powerful predictors of behavior in physical activity contexts ${ }^{13}$ and thus are used as indicators of future sports participation behavior. ${ }^{7,8,14}$ A small number of prospective studies found that intentions predict dropout behavior in youth sport, however these studies focused on only one sport. ${ }^{15,16}$ Further research is needed to determine whether these findings generalize across a range of 
sport research. Furthermore, the studies did not consider enjoyment, and it would be valuable to compare how both affective and cognitive factors relate to dropout behavior.

The present study therefore examines whether enjoyment and behavioral intentions predict dropout behavior at one-year follow-up. Previous research indicates that the decision to dropout is complex and influenced by a number of factors in addition to behavioral intentions and enjoyment. For example, research suggests that dropout is particularly evident in females as they progress through adolescence, so age and sex are important factors to consider.$^{17}$ Additionally, dropout may differ between recreational and competitive sport environments. ${ }^{3}$ Perceived competence is also considered a key determinant of youth physical activity ${ }^{18}$ with a recent systematic review by Crane and Temple ${ }^{6}$ indicating that a lack of perceived competence was the second most common intrapersonal variable associated with dropout. Crane and Temple ${ }^{6}$ further identified relationships with parents, coaches, and peers as prominent interpersonal predictors of dropout. This is supported by other research linking perceptions of parental support, quality coach-athlete relationships, peer acceptance, and quality friendships with commitment and continued participation. ${ }^{11,19-21}$

We therefore hypothesize that age, sex, competition level, perceived competence, parental support, coach-athlete relationship quality, peer acceptance, and friendship quality will be associated with sport participation behavior. However, given lack of enjoyment is the most frequently cited reason for dropout, ${ }^{6,9}$ and behavioral intentions are powerful predictors of behavior in physical activity contexts, ${ }^{13}$ we expect enjoyment and behavioral intentions will predict continued participation/dropout over and above these variables. It is expected that individuals reporting greater enjoyment and a greater intention to continue in their sport will be more likely to continue participation and less likely to drop out.

\section{Method}

\section{Participants and Procedure}


Enjoyment and Intentions as Predictors of Dropout

A total of 327 regular sport participants (i.e., reported participation in organized sport at least once per week for at least three months or an entire season over the past year) ${ }^{22}$ aged between 11 and 15 years $\left(M_{\text {age }}=13.03 ; 77\right.$ males, 250 females $)$ were recruited from two private schools in Sydney, New South Wales, Australia. Participants responded to a battery of questionnaires (approx. 15-20 minutes) assessing sports participation, enjoyment, intention to continue, perceived competence, and perceptions of key social relationships during their regular Physical Education lesson (Time 1). Participants completed the same questionnaires one-year later (Time 2), with additional sport participation/dropout questions.

\section{Measures}

Enjoyment. The Enjoyment subscale from the Sport Commitment Model ${ }^{23}$ was used to measure participants' levels of enjoyment in their main sport. Participants responded to four items (e.g., “Do you enjoy playing your main sport?”) on a 5-point scale ranging from 1 (not at all) to 5 (very much). The scale's validity and reliability has been supported in comparable populations. ${ }^{21}$ Cronbach's alpha in the current study was $\alpha=.96$.

Intention to Continue. One item was designed to measure the participant's intention to continue in their sport ("I intend to participate in my main sport next season"). Participants responded on a 5-point scale ranging from 1 (strongly disagree) to 5 (strongly agree).

Dropout. Participants were asked to nominate their main sport at Time 1 and Time 2. If participants reported sports participation at Time 2, they were asked whether their current main sport was their main sport at Time 1. Participants who responded "no" then reported whether they discontinued participating in their Time 1 main sport completely, or they continued participating in their Time 1 main sport as a secondary sport.

Covariates. Participants' age, sex, level of competition, perceptions of competence, parental support, coach-athlete relationship quality, friendship quality, and peer acceptance were included as covariates. Participants reported the competition level of their main sport as 
either basic (e.g., local club), advanced (e.g., regional representation), pre-elite (e.g., state representation), or elite (e.g., national representation). Perceived competence was assessed using the Athletic Competence subscale of the Self-Perception Profile for Children $(\alpha=$ $.78){ }^{24}$ Parental support was assessed using the Perceived Parental Support Scale $(\alpha=.78) .{ }^{25}$

Quality of the coach-athlete relationship was assessed using the Coach-Athlete Relationship Questionnaire $(\alpha=.94){ }^{26}$ Perceived friendship quality was assessed using the Sport Friendship Quality Scale $(\alpha=.90) .{ }^{27}$ Peer acceptance was assessed using the Social subscale of the Self-Perception Profile for Children $(\alpha=.82){ }^{24}$

\section{Data Analysis Plan}

For all variables, distributions were inspected and no data were removed. T-tests then examined differences between individuals who reported continued participation in their main sport and individuals who dropped out of their main sport. Hierarchical logistic regression models examined the association of Time 1 predictors with Time 2 dropout. In step 1, we modelled the covariates (age, sex, competition level, perceived competence, parental support, coach-athlete relationship quality, friendship quality, and peer acceptance) as predictors of drop out. In step 2, we added enjoyment and intention to continue. All analyses were performed using IBM SPSS statistics software (version 21).

\section{Results}

\section{Descriptive statistics}

At one-year follow-up, data were available from 273 sports participants (62 males, 211 females) aged 11 to 15 years at baseline $\left(M_{\text {age }}=13.01, S D=.83\right)$; the retention rate was 83.5\%. At Time 2, 247 (90\%; 54 males, 193 females; $M_{\text {age }}=13.04$ years) continued participation (reported the same main sport at Time 1 and Time 2 or reported a new main sport at Time 2 and continued participating in their Time 1 sport as a secondary sport), whereas 26 ( $10 \%$; 8 males, 18 females; $M_{\text {age }}=12.73$ years) had dropped out (reported 
Enjoyment and Intentions as Predictors of Dropout

complete discontinuation in the sport reported at Time 1). On average, participants who continued participation had participated in their main sport for 5.44 years $(S D=3.01)$, mostly participated in team sports $(\mathrm{n}=153,61 \%)$, and predominately at a basic competition level ( $\mathrm{n}$ $=134,54.3 \%)$. Participants who dropped out had participated in their sport for an average of 3.23 years $(S D=2.28)$ and mostly dropped out of team sports $(\mathrm{n}=14,53.8 \%)$ at a basic competition level $(\mathrm{n}=19,73 \%)$. Descriptive statistics for the study variables are presented in Table 1. Independent samples $t$ test indicated individuals who dropped out of their main sport differed significantly from those who continued participation on the main study variables.

\section{Hierarchical Logistic Regression}

The results from the hierarchical logistic regression are presented in Table 2.

Although all variables were correlated (Pearson's $r$ ranged from .16 - .58), collinearity diagnostics were computed and indicated no evidence of multicollinearity (minimum tolerance $=.52 ;$ maximum variance inflation factor $=1.93$ ). Step 1 indicated that age, parental support, coach-athlete relationship quality, and peer acceptance significantly predicted dropout behavior. With the additional inclusion of enjoyment and intention to continue, Step 2 had an improved overall model fit, a greater Nagelkerke $\mathrm{R}^{2}$ value, and a higher percentage of correct predictions. Step 2 indicated that greater enjoyment $(\mathrm{OR}=.82$; $95 \% \mathrm{CI}, .67-.99)$ and intention to continue (OR $=.41 ; \mathrm{CI}, .22-.75)$ were inversely associated with dropout. Peer acceptance was the only covariate that remained significantly associated with dropout in the presence of intentions and enjoyment.

\section{Discussion}

The current study investigated whether enjoyment and behavioral intentions to continue in youth sport predicted participation and dropout behavior at one-year follow-up. As expected, after taking into account age, sex, competitive level, parental support, coachathlete relationship quality, friendship quality, and peer acceptance, enjoyment and 
Enjoyment and Intentions as Predictors of Dropout

behavioral intentions to continue were associated with a reduced likelihood of dropout.

Therefore, as enjoyment and behavioral intentions to continue increase, the risk of dropout decreases. This suggests that in youth sport contexts where lifelong participation is a goal, youth sport stakeholders should prioritize enjoyment over other outcomes such as winning. The present study is the first to link levels of enjoyment with participation and dropout behavior using a prospective design following individuals across clubs and sports, and addresses an important methodological gap in the literature. For example, previous research that recruited through soccer clubs, and could not follow individuals who changed to a club not involved in the study, found enjoyment did not predict team-specific dropout. ${ }^{11}$ However, the present results support findings of retrospective research and use of enjoyment as a proxy measure of sport-specific dropout. ${ }^{6,14}$ The results also support the use of behavioral intentions as proxy measures within cross-sectional research, ${ }^{7,8,14}$ and corroborate the findings of other prospective research that investigated the link between intentions and dropout in a single sport. ${ }^{15,16}$ Together, findings provide evidence of both affective and cognitive antecedents of dropout behavior, as proposed by the FIT and the TPB.

Although not a central aim of the study, peer acceptance was also associated with dropout behavior. The importance of peer acceptance for enjoyment and sustained participation is consistent with the FIT $^{9}$ as three out of the eleven dimensions of fun (positive team dynamics, team friendships, team rituals) relate to peer relationships, with positive team dynamics rated the highest importance of any dimension. Given friendship quality focuses on relationships with one close friend in sport, the team/group focus of these social fundimensions may explain why it was not a significant predictor of dropout. Similarly, although the game time support dimension contains fun-determinants related to parents, these do not clearly map onto the items within the parental support scale. Additionally, previous research found positive peer relationships predicted continued participation when perceived mother 
Enjoyment and Intentions as Predictors of Dropout

212

213

214

215

216

217

218

219

220

221

223

224

225

226

228

229

230

231

234

235

236

relationship quality was low, suggesting parents may be less influential than peers in this context. ${ }^{11}$ Although the FIT identifies positive coaching as another important fun-dimension, the present study examined player perceptions alone, which may indicate that parents and coaches place more emphasis on the role of the coach than players. Chan, Lonsdale, and Fung further highlighted the influential role of peers during adolescence as they were found to be more important for athlete enjoyment and effort than parents and coaches. ${ }^{28}$

The present findings could inform interventions aimed at preventing dropout by identifying at risk individuals based on enjoyment and future intentions, exploring the factors contributing to their reduced enjoyment levels and/or future intentions, and providing support or alternative options. For example, consistent with the FIT, where perceived competence is low, providing options such as skill development programs where individuals are taught new skills while being challenged to improve and learn from mistakes may aid competence development and in turn foster enjoyment and sustained participation. ${ }^{9}$ Similarly, if reduced levels of enjoyment and intention to continue reflect difficulties surrounding peer relationships, coaches or organizers might introduce team building activities or outings which can encourage the development of friendships and positive team dynamics. Furthermore, given the significant value of sport participation for long-term health and development, ${ }^{2,4}$ individuals could be encouraged to sample other sports that they might enjoy as sport-specific dropout may be a more positive outcome than withdrawal from all sport. The findings also have implications for future research as they support the use of enjoyment and intentions as indicators of future sport participation behavior when prospective designs are not feasible. Limitations of the current study include the small number of individuals who dropped out (although the sample size was sufficient to observe small to moderate effects), the low percentage of males, and the high socioeconomic status of participants (i.e., students from private high schools); these factors limit the generalizability of findings. The high 
Enjoyment and Intentions as Predictors of Dropout

237

238

239

240

241

242

243

244

245

246

247

248

249

250

251

socioeconomic status is particularly important because socioeconomic status is inversely associated with dropout; this may partially explain the low dropout rate observed in this study. ${ }^{29}$ Future research should measure and control for SES, use larger sample sizes from a range of socioeconomic positions, and include similar proportions of males and females.

Other study limitations include the high levels of enjoyment and intention to continue reported by the sample which may indicate a ceiling effect. Although past research supports the use of single item measures,${ }^{30}$ additional items measuring intention to dropout may have allowed a clearer distinction between individuals who dropped out or continued participation. Further, the social measures focused on specific and positive aspects of relationships. Future research might include broader measures or measures that look at negative influences, such as parental, coach, and peer pressure. ${ }^{6}$ Additionally, the present research only investigated sportspecific dropout. Research with larger sample sizes should investigate whether differences exist between individuals who dropped out completely and those who dropped out of their main sport to participate in a different sport. Research might also benefit from having participants report their reasons for dropout as there are many factors that could influence their decision, such as work and study commitments or injuries.

The present research found support for the use of enjoyment and intentions as predictors of participation and dropout behavior in organized youth sport. After taking into account relevant covariates, enjoyment and intention to continue were found to significantly predict sport participation behavior. Findings support previous research using enjoyment and intentions as proxy measures of future sport participation behavior. ${ }^{7,8,14}$ Additionally, findings justify future research and intervention strategies that target enjoyment and behavioral intentions to prevent dropout. Sport organizations and coaches should aim to establish enjoyable and supportive environments whilst monitoring sports participants' enjoyment levels and future intentions throughout the season. 


\section{References}

263 1. Tremblay MS, Gray CE, Akinroye KK, et al. Physical activity of children: A global matrix of grades comparing 15 countries. J Phys Act Health. 2014;11:S113-S125.

2. Bailey R, Hillman C, Arent S, Petitpas A. Physical activity: An underestimated investment in human capital? J Phys Act Health. 2013;10:289-308.

3. Balish SM, McLaren C, Rainham D, Blanchard C. Correlates of youth sport attrition: A review and future directions. Psychol Sport Exerc. 2014;15:429-439.

4. Vella SA, Cliff DP, Magee CA, Okely AD. Sports participation and parent-reported health-related quality of life in children: Longitudinal associations. J Pediatr. 2014;164:1469-1474.

5. Vella SA, Cliff DP, Magee CA, Okely AD. Associations between sports participation and psychological difficulties during childhood: A two-year follow up. J Sci Med Sport. 2015;18:304-309.

6. Crane J, Temple V. A systematic review of dropout from organized sport among children and youth. Eur Phys Educ Rev. 2015;21:114-131.

7. Gardner LA, Magee CA, Vella SA. Social climate profiles in adolescent sports: Associations with enjoyment and intention to continue. J Adolesc. 2016;52:112-123.

8. Atkins MR, Johnson DM, Force EC, Petrie TA. Peers, parents, and coaches, oh my! The relation of the motivational climate to boys' intention to continue in sport. Psychol Sport Exerc. 2015;16:170-180.

9. Visek AJ, Achrati SM, Mannix HM, McDonnell K, Harris BS, DiPietro L. The fun integration theory: Toward sustaining children and adolescents sport participation. $J$ Phy Act Health. 2015;12:424-433.

10. Morrow B. An overview of cohort study designs and their advantages and disadvantages. Int J Ther Rehabil. 2010;17:518-523. 
Enjoyment and Intentions as Predictors of Dropout

11. Ullrich-French S, Smith AL. Social and motivational predictors of continued youth sport participation. Psychol Sport Exerc. 2009;10:87-95.

12. Ajzen I. The theory of planned behavior. Organ Behav Hum Decis Process. 1991;50:179-211.

13. Hagger MS, Chatzisarantis NL, Biddle SJH. A meta-analytic review of the theories of reasoned action and planned behavior in physical activity: Predictive validity and the contribution of additional variables. J Sport Exerc Psychol. 2002;24:3-32.

14. Gardner LA, Vella SA, Magee CA. Continued Participation in Youth Sports: The Role of Achievement Motivation. J Appl Sport Psychol. 2016:1-15.

15. Sarrazin P, Vallerand R, Guillet E, Pelletier L, Cury F. Motivation and dropout in female handballers: A 21-month prospective study. Eur J Soc Psychol. 2002;32:395418.

16. Nache CM, Bar-Eli M, Perrin C, Laurencelle L. Predicting dropout in male youth soccer using the theory of planned behavior. Scand J Med Sci Spor. 2005;15:188-197.

17. Eime RM, Harvey JT, Sawyer NA, Craike MJ, Symons CM, Payne WR. Changes in sport and physical activity participation for adolescent females: A longitudinal study. BMC Public Health. 2016;16:1-7.

18. Babic M, Morgan P, Plotnikoff R, Lonsdale C, White R, Lubans D. Physical Activity and Physical Self-Concept in Youth: Systematic Review and Meta-Analysis. Sports Medicine. 2014;44:1589-1601.

19. Nunomura M, Oliveira MS. Parents' support in the sports career of young gymnasts. Sci Gymnastics J. 2013;5:5-17.

20. Rottensteiner C, Konttinen N, Laakso L. Sustained participation in youth sports related to coach-athlete relationship and coach-created motivational climate. International Sport Coaching Journal. 2015;2:29-38. 
Enjoyment and Intentions as Predictors of Dropout

21. McDonough MH, Crocker PRE. Sport participation motivation in young adolescent girls: The role of friendship quality and self-concept. Res $Q$ Exerc Sport. 2005;76:456-467.

22. Active Healthy Kids Australia. Is sport enough? 2014 report card on physical activity for children and young people. Australia2014.

23. Scanlan TK, Simons JP, Carpenter PJ, Schmidt GW, Keeler B. The Sport Commitment Model: Measurement development for the youth-sport domain. J Sport Exerc Psychol. 1993;15:16-38.

24. Harter S. Manual for the self-perception profile for children. Denver: University of Denver; 1985.

25. Van Yperen NW. Interpersonal stress, performance-level, and parental support: A longitudinal-study among highly skilled young soccer players. Sport Psychol. $1995 ; 9: 225-241$.

26. Jowett S, Ntoumanis N. The coach-athlete relationship questionnaire (CART-Q): Development and initial validation. Scand J Med Sci Spor. 2004;14:245-257.

27. Weiss MR, Smith AL. Quality of youth sport friendships: Measurement development and validation. J Sport Exerc Psychol. 1999;21:145-166.

28. Chan DK, Lonsdale C, Fung HH. Influences of coaches, parents, and peers on the motivational patterns of child and adolescent athletes. Scand J Med Sci Spor. 2012;22:558-568.

29. Vella SA, Cliff DP, Okely AD. Socio-ecological predictors of participation and dropout in organised sports during childhood. Int J Behav Nutr Phys Act. 2014;11:6271.

30. Bergkvist L. Appropriate use of single-item measures is here to stay. Mark Lett. $2015 ; 26: 245-255$. 
Enjoyment and Intentions as Predictors of Dropout

337

338

Table 1

Descriptive Statistics

\begin{tabular}{lccrrrr}
\hline & & $\begin{array}{c}\text { Discontinued } \\
\text { Participation } \\
(\mathrm{n}=26)\end{array}$ & $\begin{array}{c}\text { Continued } \\
\text { Participation } \\
(\mathrm{n}=247)\end{array}$ \\
\cline { 2 - 7 } & Scale & $M$ & $S D$ & \multicolumn{1}{c}{$M$} & $S D$ \\
\hline Enjoyment & $1-5$ & $3.75^{\mathrm{a}}$ & 1.09 & $4.76^{\mathrm{b}}$ & .51 \\
Intention to Continue & $1-5$ & $3.54^{\mathrm{a}}$ & 1.24 & $4.68^{\mathrm{b}}$ & .60 \\
Perceived Competence & $1-4$ & $2.42^{\mathrm{a}}$ & .65 & $2.80^{\mathrm{b}}$ & .56 \\
Parental Support & $1-5$ & $3.86^{\mathrm{a}}$ & .82 & $4.23^{\mathrm{b}}$ & .65 \\
Coach-Athlete Relationship Quality & $1-7$ & $4.73^{\mathrm{a}}$ & 1.24 & $5.74^{\mathrm{b}}$ & 1.01 \\
Friendship Quality & $1-5$ & $3.86^{\mathrm{a}}$ & .64 & $4.12^{\mathrm{b}}$ & .58 \\
Peer Acceptance & $1-4$ & $2.53^{\mathrm{a}}$ & .45 & $3.00^{\mathrm{b}}$ & .64 \\
\hline Note. Means in the same row with the different superscripts are significantly \\
different from each other at $p<.05$.
\end{tabular}

Table 2.

Hierarchical Logistic Regression Results

\begin{tabular}{|c|c|c|c|c|c|c|}
\hline \multirow[b]{2}{*}{ Variable } & \multicolumn{3}{|c|}{ Step 1} & \multicolumn{3}{|c|}{ Step 2} \\
\hline & B & SE & $\begin{array}{l}\text { Odds Ratio } \\
(95 \% \mathrm{CI})\end{array}$ & B & SE & $\begin{array}{l}\text { Odds Ratio } \\
(95 \% \mathrm{CI})\end{array}$ \\
\hline Constant & 16.97 & 5.03 & - & 18.11 & 5.80 & -1 \\
\hline Age & $-.73 *$ & .31 & $.48(.26-.88)$ & -.64 & .35 & $.53(.27-1.04)$ \\
\hline Sex & -.69 & .55 & $.50(.17-1.46)$ & -.55 & .59 & $.58(.18-1.82)$ \\
\hline Level & -.14 & .28 & $.87(.50-1.52)$ & -.02 & .32 & $.98(.52-1.83)$ \\
\hline Perceived & -.07 & .07 & $.93(.81-1.08)$ & .03 & .09 & $1.03(.87-1.23)$ \\
\hline \multicolumn{7}{|l|}{ Competence } \\
\hline Parental Support & $-.16^{*}$ & .08 & $.85(.73-1.00)$ & -.16 & .09 & $.86(.72-1.02)$ \\
\hline $\begin{array}{l}\text { Coach-athlete } \\
\text { relationship quality }\end{array}$ & $-.06^{* *}$ & .02 & $.94(.90-.97)$ & -.008 & .02 & $.99(.95-1.04)$ \\
\hline Friendship Quality & .01 & .02 & $1.01(.98-1.05)$ & .01 & .02 & $1.01(.97-1.06)$ \\
\hline Peer Acceptance & $-.14 *$ & .07 & .87 (.76-.99) & $-.15^{*}$ & .08 & .86 (.74-.99) \\
\hline Enjoyment & & & & $-.20 *$ & .10 & $.82(.67-.99)$ \\
\hline Intention & \multirow{2}{*}{\multicolumn{3}{|c|}{133.67}} & $-.90 * *$ & .31 & $.41(.22-.75)$ \\
\hline -2 Log likelihood & & & & \multicolumn{3}{|c|}{113.27} \\
\hline Model Chi-Square & \multicolumn{3}{|c|}{$37.03, d f=8, p<.001$} & \multicolumn{3}{|c|}{$57.43, d f=10, p<.001$} \\
\hline Nagelkerke $\mathrm{R}^{2}$ & \multicolumn{3}{|c|}{274} & \multicolumn{3}{|c|}{.409} \\
\hline $\begin{array}{l}\text { Classification } \\
\text { Accuracy }\end{array}$ & \multicolumn{3}{|c|}{$90.7 \%$} & \multicolumn{3}{|c|}{$93.7 \%$} \\
\hline
\end{tabular}

Note. $* p<.05, * * p<.01$ 